\title{
Meningococcal antibody titres in infants of women immunised with meningococcal polysaccharide vaccine during pregnancy
}

Timothy J D O'Dempsey, Theresa McArdle, Serign J Ceesay, Ousman Secka, Edward Demba, Winston A S Banya, Nicholas Francis, Brian M Greenwood

\begin{abstract}
Seventy five Gambian women were immunised with a single dose of a group A+group C meningococcal polysaccharide vaccine during the last trimester of pregnancy. IgG antibody titres were measured in mothers and in their infants by an enzyme-linked immunosorbent assay (ELISA). All women had a good response to vaccination and maternal antibodies were high at the time of delivery $(23 \cdot 2 \mu \mathrm{g} / \mathrm{ml}$ for group $A$ antibodies and $14 \cdot 3 \mu \mathrm{g} / \mathrm{ml}$ for group $\mathrm{C}$ antibodies). However, only a proportion of this antibody crossed the placenta; cord blood:maternal antibody ratios were $30 \%$ for group $A$ antibody and $44 \%$ for group C antibody, respectively. Considerable variability in cord blood:maternal blood ratios was seen between individuals. This could not be related to age, parity, or ethnic group. Mean group $A$ and group $C$ cord blood:maternal blood ratios were lower in women with serological evidence of syphilis than in seronegative women, and diminished transfer of group $A$ antibody was noted in women with active malarial infection of the placenta. Antibody titres declined rapidly in infants and by the age of 3-4 months these had reached control values.
\end{abstract}

Maternal immunisation may give infants some protection against group $A$ and group $C$ meningococcal disease but only during the first few months of life. (Arch Dis Child 1996; 74: F43-F46)

Keywords: meningococcal polysaccharide vaccine, cord blood:maternal antibody ratios, placental transfer, immunity.

Medical Research Council Laboratories, Fajara, Banjul, The Gambia

T J D O'Dempsey

$T$ McArdle

S J Ceesay

O Secka

E Demba

W A S Banya

B M Greenwood

Department of Histopathology, Charing Cross Hospital, London N Francis

Correspondence to: Dr B M Greenwood, London School of Hygiene and Tropical Medicine, Keppel St, London WC1E $7 \mathrm{HT}$.

Accepted 9 August 1995 the young. Meningococcal polysaccharide vaccines, effective at stopping epidemics, are poor immunogens in young children. However, the recent development of group A and group $\mathrm{C}$ meningococcal polysaccharide/protein conjugate vaccines, which are immunogenic in young infants, provides a potential way of overcoming this problem. ${ }^{67}$ If meningococcal conjugate vaccines are introduced into expanded programmes of immunisation then it is likely that they will be given at the ages of 2-4 months with diphtheria-pertussis-tetanus vaccine, as is now the case for Hib conjugate vaccines. Adoption of such an immunisation schedule would mean that infants would be dependent for protection against meningococcal disease during their first few months of life, when meningococcal infections are common, once antibody has transferred across the placenta.

In many communities a substantial proportion of mothers will have inadequate meningococcal antibodies to provide this protection. We therefore investigated the feasibility of enhancing passive protection to meningococcal disease in infants by immunising their mothers with meningococcal polysaccharide vaccines during pregnancy.

\section{Methods}

The study was carried out at Basse, Upper River Division (URD), The Gambia, between July 1991 and February 1992. One hundred and fifty women (50 primigravidae and 100 multigravidae) who lived in or near to Basse were recruited when they presented to the antenatal clinic at Basse Health Centre. After consent had been obtained, women were examined by a project physician, a urine sample obtained for protein testing, and a blood sample obtained for preparation of a thick blood film, determination of the packed cell volume (PCV), and for VDRL testing. Women found to have malaria or a positive VDRL were treated with chloroquine and benzanthine penicillin, respectively, and all women were supplied with iron and folate tablets. Women were then randomly allocated to receive either a single injection of meningococcal group A+group C polysaccharide vaccine (Pasteur Mérieux) containing $50 \mu \mathrm{g}$ of group $\mathrm{A}$ and group $\mathrm{C}$ polysaccharides or a single injection of a 23-valent pneumococcal polysaccharide vaccine (Pasteur Mérieux) (types 1, 2, 3, 4, 5, $6 \mathrm{~B}, 7 \mathrm{~F}, 8,9 \mathrm{~N}, 9 \mathrm{~V}, 10 \mathrm{~A}, 11 \mathrm{~A}, 12 \mathrm{~F}, 14,15 \mathrm{~B}$, $17 \mathrm{~F}, 18 \mathrm{C}, 19 \mathrm{~F}, 19 \mathrm{~A}, 20,22 \mathrm{~F}, 23 \mathrm{~F}$, and $33 \mathrm{~F}$ ). Study women were encouraged to deliver at the Basse Health Centre. 
During the antenatal period, mothers continued to attend antenatal clinics at Basse Health Centre and were encouraged to attend the MRC clinic if they were unwell. Mothers were also visited at home by MRC field staff to check on their progress. MRC transport was provided to bring women to the health centre for delivery and their delivery fees were paid. Whenever possible, MRC staff were present at the time of delivery or they visited mothers and infants within 24 hours of delivery. Infants were then randomly allocated to receive follow up visits at 1,3 , and 5 months or 2,3 , and 4 months of age. However, because mothers frequently travelled, not all follow up visits were made at the correct time. Free access to the MRC clinic at Basse was provided to mothers and infants throughout the period of the study. The physician who saw study children in the clinic did not know the vaccine group to which a child belonged.

Women in the meningococcal and pneumococcal vaccine groups were well matched for age, parity, and gestational age at the time of vaccination. Clinical and laboratory findings in women who received pneumococcal vaccine will be presented separately.

Background antibody titres during the first few months of life in infants whose mothers had not been vaccinated were measured in sera collected during the course of a meningococcal polysaccharide/conjugate vaccine trial carried out in the same community at the same time. ${ }^{7}$

\section{LABORATORY METHODS}

Blood film examination for malaria parasites, measurement of packed cell volume (PCV), and Venereal Disease Research Laboratory (VDRL) tests were done by standard methods. Placental samples were collected with a corkborer from the maternal side of the placenta, fixed in buffered formol-saline, and stained with haematoxylin and eosin. The histology of the placenta was assessed in relation to the presence or absence of features of malaria infection, as described before. ${ }^{8}$

Antibodies to group $\mathrm{A}$ and group $\mathrm{C}$ meningococcal polysaccharides were measured at MRC Fajara by ELISAs, as described before. ${ }^{9}{ }^{10}$ An IgG conjugate was used. Results are expressed in relation to a standard reference serum ascribed total and class-specific antibody concentrations for group $A$ and group C meningococcal polysaccharides. ${ }^{10}$ Antibody measurements in the sera of infants whose mothers had not been immunised were undertaken at the CDC, Atlanta, using the same ELISA, the same standard serum, and the same controls.

\section{STATISTICAL METHODS}

Data were analysed using the statistical package Statistical Analysis Systems (SAS). All skewed variables, including antibody titres, were log transformed before analysis. Student's $t$ test was used for comparisons between means and Pearson's correlation coefficient for comparisons between two variables.
The study was approved by the Gambia Government/MRC Ethical Committee.

\section{Results}

Seventy five women, 25 primigravidae and 50 multigravidae, were immunised with a group A+group C meningococcal polysaccharide vaccine during the last trimester of pregnancy. Their mean age was 22 years (95\% CI 20, 23 years) and their mean gestational age at the time of vaccination, as assessed by clinical assessment of fundal height, was 36 weeks ( $95 \%$ CI 34,38 weeks). The mean interval between the time of vaccination and delivery was seven weeks ( $95 \%$ CI 6, 8 weeks). Forty four women delivered at the Basse Health centre, 29 at home and two elsewhere. One woman moved away before delivery. There were no maternal deaths. Three babies delivered at home were stillborn. One stillbirth was associated with abruption of the placenta and another with a cord prolapse; the cause of the third stillbirth was not known. There was one neonatal death, giving a perinatal death rate of 54 per 1000 .

Maternal and cord blood samples were obtained from 62 mother-child pairs; in the remaining cases women delivered at home without notifying project staff or refused to give a blood sample. Unfortunately, samples from 11 pairs had to be discarded due to loss of labels during transit or collection of insufficient serum, leaving 51 mother-child pairs. In six cases serum volumes were sufficient only for the determination of group A meningococcal antibodies. Infants were bled by finger-prick on three occasions during the first six months of life, either at the ages of 1,3 , and 5 months or at 2,4 , and 6 months. Because infants were not always available on the appointed day, the numbers of samples tested for each month of age are unequal.

\section{ANTIBODY RESPONSE TO VACCINATION}

Pregnant women showed a good antibody response to both the group $\mathrm{A}$ and group $\mathrm{C}$ components of the vaccine (table 1); antibody titres increased five and seven fold, respectively, after vaccination. Mean increases in GMT were similar in primigravidae and in multigravidae and were not influenced by age or by ethnic group. Seven women had a positive blood film for malaria at the time of vaccination and four a positive VDRL. Mean increases in GMT were less in women with a positive malaria blood film than in those who were negative $-3.8(95 \% \mathrm{CI}, 2 \cdot 5,5 \cdot 9)$ v $5 \cdot 1$ $(95 \% \mathrm{CI} 4.0,6 \cdot 6)$ for group $\mathrm{A}$ antibodies and $11.2(95 \%$ CI $8.6,14 \cdot 7)$ v 6.4 (95\% CI 3.9, 10.5) for group $C$ antibodies, respectively, but neither of these differences was significant $(t=0.89 ; P=0.37$ and $t=1.6 ; P=0.11$, respectively). Antibody responses were not influenced by VDRL positivity. Maternal antibody responses at the time of vaccination were not correlated significantly with the interval between vaccination and delivery $(r=0 \cdot 24$; $\mathrm{P}=0.09$ and $\mathrm{r}=0.02 ; \mathrm{P}=0.91$ for group $\mathrm{A}$ and group $\mathrm{C}$ antibodies, respectively). 
Table 1 Group $A$ and group $C$ meningococcal polysaccharide antibody titres in pregnant women before and after vaccination with a single dose of group $A+C$ meningococcal polysaccharide vaccine, in cord blood, and in the serum of their infants during their first few months of life

\begin{tabular}{|c|c|c|c|c|}
\hline \multirow[b]{3}{*}{ Group } & \multicolumn{4}{|l|}{ Antibody } \\
\hline & \multicolumn{2}{|l|}{ Group $A$ antibody } & \multicolumn{2}{|l|}{ Group $C$ antibody } \\
\hline & Vaccinated & Control & Vaccinated & Control \\
\hline Women: & & & & \\
\hline Pre-vaccination & $\begin{array}{c}4 \cdot 7 \underset{(31)}{(3 \cdot 8,5 \cdot 9)} \\
\text { (51) }\end{array}$ & & $\begin{array}{c}1 \cdot 9(1 \cdot 5,2 \cdot 6) \\
(45)\end{array}$ & \\
\hline Post-vaccination (at delivery) & $\begin{array}{c}23 \cdot 2 \underset{(51)}{(19 \cdot 0,28 \cdot 4)} \\
\text { (5) }\end{array}$ & & $\begin{array}{c}14 \cdot 3 \underset{(45)}{(11 \cdot 2,18 \cdot 4)} \\
\text { (4) }\end{array}$ & \\
\hline Cord blood: & $\begin{array}{c}6 \cdot 7(5 \cdot 2,8 \cdot 5) \\
(51)\end{array}$ & & $\begin{array}{c}5 \cdot 8(4 \cdot 5,7 \cdot 5) \\
(45)\end{array}$ & \\
\hline $\begin{array}{l}\text { Infants: } \\
1 \text { Month }\end{array}$ & $\begin{array}{c}2 \cdot 0(1 \cdot 4,3 \cdot 0) \\
(24)\end{array}$ & & $\begin{array}{c}1 \cdot 5(0 \cdot 8,2 \cdot 8) \\
(21)\end{array}$ & \\
\hline 2 Months & $\begin{array}{c}1 \cdot 9(1 \cdot 2,2 \cdot 9) \\
(22)\end{array}$ & $\begin{array}{c}0.7(0.5,0.9) \\
(154)\end{array}$ & $\begin{array}{c}1 \cdot 8(1 \cdot 2,2 \cdot 6) \\
(21)\end{array}$ & $\begin{array}{c}0.4(0.3,0.7) \\
(138)\end{array}$ \\
\hline 3 Months & $\begin{array}{c}0.5(0.3,0 \cdot 8) \\
(42)\end{array}$ & $\begin{array}{c}0.6(0.5,0.7) \\
(47)\end{array}$ & $\begin{array}{c}0.5(0.3,0.8) \\
(40)\end{array}$ & $\begin{array}{c}0.3(0.2,0.5) \\
(45)\end{array}$ \\
\hline 4 Months & $\begin{array}{c}0 \cdot 1(0 \cdot 1,0 \cdot 4) \\
(21)\end{array}$ & & $\begin{array}{c}0 \cdot 1(<0 \cdot 1,0 \cdot 3) \\
(18)\end{array}$ & \\
\hline 5 Months & $\begin{array}{c}0 \cdot 1(0 \cdot 1,0 \cdot 1) \\
(41)\end{array}$ & & $\begin{array}{c}0 \cdot 1(<0 \cdot 1,0 \cdot 2) \\
(36)\end{array}$ & \\
\hline 6 Months & & $\begin{array}{c}0.4 \underset{(55)}{(0.4,0.5)} \\
(55)\end{array}$ & & $\begin{array}{c}0.2(0.1,0.2) \\
(51)\end{array}$ \\
\hline
\end{tabular}

Values in infants of unimmunised mothers are also shown. GMT with $95 \% \mathrm{CI}(\mu \mathrm{g} / \mathrm{ml})$ are shown; follow on figures in parentheses indicate the number of observations made.

\section{PLACENTAL TRANSFER OF MENINGOCOCCAI} ANTIBODY

Ratios of group A and group C meningococcal antibodies in cord blood to those in maternal blood collected at the same time were determined for each mother-infant pair. This ratio differed widely between pairs with maximum and minimum levels, ranging from $68 \%$ to $8 \%$ for group A antibodies and from $91 \%$ to $7 \%$ for group $\mathrm{C}$ antibody. The mean cord blood:maternal blood ratio for group A antibody was $30 \%$ (95\% CI $26 \%, 34 \%$ ) and for group C antibody it was $42 \%$ (95\% CI $35 \%$, 49\%). Concordance between cord blood: maternal blood ratios for group A antibody and for group $\mathrm{C}$ antibody in individual mother-infant pairs was poor, but just significant $(r=0.30 ; P=0.05)$.

Various factors were investigated to see if these could account for the wide variation in ratios found between individual mother-infant pairs. There was little correlation between the amount of maternal antibody and the percentage transferred across the placenta $(r=0 \cdot 10$; $\mathrm{P}=0.48$ for group $\mathrm{A}$ antibodies and $\mathrm{r}=-0.29$; $\mathrm{P}=0.05$ for group $\mathrm{C}$ antibodies). Mean ratios for both group $\mathrm{A}$ and group $\mathrm{C}$ antibodies were similar in primigravidae and multigravidae (32\% (95\% CI 25\%, 40\%) v 28\% (95\% CI

Table 2 Group $A$ and group $C$ meningococcal polysaccharide antibody titres in cord blood samples compared with maternal blood samples collected at the same time in relation to histological evidence of malaria infection of the placenta

\begin{tabular}{lll}
\hline & \multicolumn{2}{l}{$\begin{array}{l}\text { Percentage cord blood antibody/ } \\
\text { maternal blood antibody }\end{array}$} \\
\cline { 2 - 3 } $\begin{array}{l}\text { Malaria infection } \\
\text { of the placenta }\end{array}$ & Group $A$ & Group C \\
\hline None & $36(28,48)$ & $39(23,66)$ \\
Chronic & $(9)$ & $(8)$ \\
Chronic + active & $30(23,40)$ & $52(43,62)$ \\
Active & $30(25,36)$ & $(8)$ \\
& $23(18)$ & $(15,35)$ \\
& $(9)$ & $44(33,63)$ \\
& & $(7)$ \\
\hline
\end{tabular}

GMT together with $95 \%$ CI are shown; follow on figures in parentheses indicate the number of observations made.
24\%, 33\%) for group A antibodies and 54\% (95\% CI 39\%, 79\%) v 38\% (95\% CI 30\%, $47 \%$ ) for group C antibodies). Ratios were not affected significantly by age at the time of vaccination or by ethnic group. The mean cord blood:maternal blood ratio for the four women who were VDRL positive when first seen was lower than that of the 42 VDRL negative women but the difference between groups was not significant. The effect of malaria infection of the placenta on the transfer of antibodies is shown in table 1. Transfer of group A antibody across the placenta was lower in women with active infection of the placenta than in other women $(t=1 \cdot 76 ; P=0.09)$ but this was not the case for group $\mathrm{C}$ meningococcal antibody titres. Cord blood:maternal blood ratios were not correlated significantly with estimated gestational age at the time of vaccination, gestational age at the time of delivery, or with birthweight.

\section{ANTIBODY TITRES IN INFANTS}

Antibody titres in the infants of vaccinated mothers during the first few months of life are shown in table 2 . Both group A and group C antibodies fell rapidly in infants of vaccinated mothers, and by the age of 3-4 months were similar to those found in control children whose mothers had not been vaccinated. Group $\mathrm{A}$ and group $\mathrm{C}$ antibodies declined at an exponential rate with a half life of about 20 days.

\section{Discussion}

Gambian women immunised with a group A+group C meningococcal polysaccharide vaccine during the last trimester of pregnancy showed a good antibody response to both components of the vaccine and had high antibody titres at the time of delivery. No immediate side effects were noted following vaccination, and perinatal morbidity and mortality, although high, were comparable with 
levels found in the study community in the absence of any intervention. ${ }^{11}$

We found that the ratio of IgG meningococcal antibody in cord blood to that in maternal blood was much lower than that described for most antibodies such as those to tetanus toxoid and to various viral proteins. ${ }^{12} \mathrm{~A}$ possible explanation for this finding is that it reflects a peculiarity of antibodies measured by ELISA, but this seems unlikely. Subclass assays were not done but the meningococcal polysaccharide vaccine is likely to have induced a good IgG1 response, a subclass that is usually transferred well across the placenta. A conjugate vaccine, by increasing immunogenicity and by altering proportions of IgG subclass, might achieve better antibody transfer. Furthermore, a low cord blood:maternal blood ratio (53\% for group A antibody) was found also in a Brazilian study of maternal immunisation with a meningococcal polysaccharide vaccine ${ }^{13}$ and low ratios have been described for antibodies to pneumococcal and Hib polysaccharides, suggesting the possibility that antibodies to polysaccharide antigens are handled in an unusual way by the placenta.

A prominent feature of our study was the variability in antibody transfer observed between different mothers. We could not identify any dominant factor that could account for this noticeable variability. Gestational age has an important influence on cord blood IgG but we did not find a correlation between cord blood:maternal blood ratios and gestational age, probably because all study women were full term. Cord blood:maternal blood ratios were not influenced by age, parity, or ethnic group. A positive VDRL and active malaria infection of the placenta had weak suppressive effects on antibody transfer, suggesting that this may be impaired by infection of the placenta. Active malaria infection has recently been shown to impair the transfer of tetanus antibodies across the placenta. ${ }^{14}$ Women were not tested for HIV but the prevalence of this infection in the study community was less than $2 \%$ at the time of the trial.

The primary purpose of the study was to determine whether an effective level of immunity to group $\mathrm{A}$ and group $\mathrm{C}$ meningococcal infection could be induced in infants during the first few months of life by immunising their mothers during pregnancy. Cord blood concentrations were much lower than those of maternal blood at the time of delivery, and antibody titres declined rapidly during the first few months of life so that by the age of 4 months antibody titres were little different from those found in control infants of the same age. These findings are in keeping with the results of two previous studies of maternal immunisation with meningococcal polysaccharide vaccines undertaken in Brazil. ${ }^{13} 15$

The amount of antibody, as measured by ELISA, that gives protection against meningococcal disease is not known and so it is uncertain if the infants in our study would have been protected against meningococcal infection and, if so, for how long. However, their antibody titres were substantially higher than those of control children of the same age during their first 3 months of life so that it is likely they would have obtained some increased protection against meningococcal disease during the period before a high level of protection could be achieved by active immunisation with a conjugate vaccine at 2,3 , and 4 months of age. It is possible that maternal immunisation could interfere with subsequent immunisation of infants. However, it has been shown recently that this is not the case in the infants of Gambian women immunised with Hib vaccine during pregnancy (Mulholland et al, submitted), but it would need to be shown that this is also the case for a meningococcal polysaccharide or conjugate vaccine before widespread immunisation during pregnancy could be undertaken.

We thank Dr George Carlone and his colleagues at the CDC, Atlanta, USA, for their help in establishing the meningococcal ELISA in The Gambia. We thank also the field staff based at Basse who undertook follow up of study subjects and the Basse who undertook follow up of study subjects and the
mothers who agreed to participate in the trial. Meningococcal mothers who agreed to participate in the trial. Meningococcal
vaccine was provided by Pasteur Mérieux. The study was vapported by the UK Medical Research Council and by USAID.

1 Goldacre MJ. Acute bacterial meningitis in childhood. Lancet 1976; i: 28-31.

2 Palmer SR, Corson J, Hall R, et al. Meningococcal disease in Wales: clinical features, outcome and public health management. F Infect 1992; 25: 321-8.

3 Fortnum HM, Davis AC. Epidemiology of bacterial meningitis. Arch Dis Child 1993; 68: 763-7.

4 Baker CJ, Griffiss JM. Influence of age on serogroup distribution of endemic meningococcal disease. Pediatrics 1983; 71: 923-6.

5 Dankner WM, Ginsberg MM, Davis CE. Meningococcal disease in a pediatric population in San Diego County. Pediatr Infect Dis $\mathcal{F} 1993$; 12: 98-9.

6 Constantino P, Viti S, Podda A, Velmonte MA, Nencioni L, Rappuoli R. Development and phase 1 clinical testing of a conjugate vaccine against meningococcus $A$ and $C$. Vaccine 1992; 10: 691-8.

7 Twumasi PA, Kumah S, Leach A, et al. A trial of a group A + group C meningococcal polysaccharide/protein conjugate vaccine in African infants. F Infect Dis 1995; 171: gate vacci.

8 Bulmer IN, Rasheed FNR, Francis N, Morrison L, Greenwood BM. Placental malaria. 1. Pathological classification. Histopathology 1993; 22: $211-8$.

9 Carlone GM, Frasch CE, Siber GR, et al. Multicenter comparison of levels of antibody to the Neisseria meningitidis group A capsular polysaccharide measured using an enzyme-linked immunosorbent assay. $\mathcal{f}$ Clin Microbiol 1992; 30: 154-9.

10 Holder PK, Maslanka SE, Pais LB, Dykes J, Plikaytis BD, Carlone GM. Assignment of Neisseria meningitidis serogroup $A$ and $C$ class specific anticapsular antibody concentrations to the new standard reference serum CDC 1992. Clin Diagn Lab Immunol 1995; 2: 132-7.

11 De Francisco A, Hall AJ, Armstrong Schellenberg JRM, Greenwood AM, Greenwood BM. The pattern of infant and childhood mortality in Upper River Division, The and childhood mortality in Upper River Divisi

12 Sato H, Albrecht P, Reynolds DW, Stagno S, Ennis FA. Transfer of measles, mumps, and rubella antibodies from mother to infant. Am F Dis Child 1979; 133: 1240-3.

13 Carvalho A de A, Giampaglia CMS, Kimura H, et al. Maternal and infant antibody response to meningococcal vaccination in pregnancy. Lancet 1977 ; ii: $809-11$.

14 Brair M-E, Brabin BJ, Milligan P, Maxwell S, Hart CA. Reduced transfer of tetanus antibodies with placental malaria. Lancet 1994; 343: 208-9.

15 McCormick JB, Gusmão HH, Nakamura S, et al. Antibody response to serogroup $\mathrm{A}$ and $\mathrm{C}$ meningococcal polysaccharides vaccines in infants born of mothers vaccinated during pregnancy. $\mathcal{F}$ Clin Invest 1980; 65: 1141-4. 